\title{
Analyzing highly cited papers in Intelligent Transportation Systems
}

\author{
J.A. Moral-Muñoz, M.J. Cobo, F. Chiclana, A. Collop, E. Herrera-Viedma
}

\begin{abstract}
Citation classics offer an outlook on those papers that have attracted great and historical interest by a research community, and that could also be considered as the basis of the research field. A new approach, called H-Classics, has been developed to identify such highly cited papers. It is based on the H-index and is sensitive to both the own characteristics of the corresponding research discipline and its evolution. The present study provides a useful insight into the development of the Intelligent Transport Systems research field, revealing those scientific actors (authors, countries and institutions) that have made the biggest research contribution to its development.
\end{abstract}

Index Terms-H-index-index, Highly cited papers, H-Classics, Bibliometrics, Intelligent Transportation Systems

\section{INTRODUCTION}

The Intelligent Transportation Systems (ITS) field appeared in the 1980s when a small group of transportation professionals recognized the impact the use of computing and communications technologies could have on surface transportation [1]. ITS involves many different areas such as electronics, control, communications, sensing, robotics, signal processing and information systems [2]. It is a global phenomenon, attracting worldwide interest from transportation professionals, automotive industry and political decision makers. Furthermore, its high scientific production suggests that ITS is developing at a fast pace [2], [3].

Recently, a series of papers have been published that focus on the bibliometric impact of the ITS research field. Wang et al. (2009) [4] analyzed the first decade of research publications in the journal IEEE Transactions on Intelligent Transportation Systems (T-ITS). Wang (2010) [5] analyzed the T-ITS publication stages from 2000 to 2009. Li et al. (2010) [6] revealed the collaboration patterns and research topic trends in T-ITS, while Cobo et al. (2012) [7] completed this study with an analysis that detected, visualized, and evaluated the conceptual ITS themes and ITS thematic areas. Recently, Cobo et al. (2014) [3] highlighted the conceptual structure of the ITS research field in the period 1992-2011 by analyzing the most important ITS journals. Tang et al. (2014) [8] classified and analyzed the core articles from all the published papers in the journal T-ITS during the period 2010-2013. Finally, Wang

J.A. Moral-Muñoz is with the Dept. Library Science, University of Granada, Spain (e-mail: jamoral@ugr.es)

M.J. Cobo is with the Dept. Computer Science, University of Cádiz, Spain (e-mail: manueljesus.cobo@uca.es)

F. Chiclana and A. Collop are with the School of Computer Science and Informatics, Faculty of Technology, De Montfort University, UK. (email: \{chiclana,acollop\}@dmu.ac.uk)

E. Herrera-Viedma is with the Dept. Computer Science and A.I. (CITICUGR), University of Granada, Spain (e-mail: viedma@decsai.ugr.es). et al. (2014) [9] measured the productivity and collaboration patterns of T-ITS between 2010 and 2013.

Although the ITS field has been analyzed socially and conceptually with bibliometric tools, this is not the case for the highly cited papers of this research field. Highly cited papers could be considered important in a research field development because they have attracted the interest of the research community. In 1977, Garfield [10] introduced the bibliometric concept of "citation classic", also called "classic article" or "literary classic", to characterize the highly cited papers of a scientific discipline. Citation classics help discover potentially important information towards the development of a discipline and understand its past, present and future scientific structure, thus they are considered the "gold bullion of science" [11], [12]. Recently, an approach based on the well-known H-index [13], called H-Classics, has been developed by Martínez et al. [14] to identify the highly cited papers of a research field that also overcomes the drawbacks associated to traditional approaches.

In this paper, an analysis of the highly cited papers in the ITS research field using the H-Classics is presented., which aims to complete the series of bibliometric studies on ITS mentioned before. In such a way, additional information to understand the scientific structure of the ITS field is provided.

The rest of the paper is organized as follow: Section II shows the approach used in the analysis. Section III presents the results of our analysis. Finally, conclusions are drawn in Section IV.

\section{BIBLIOMETRIC ANALYSIS AND DATA}

\section{A. Data sources}

The bibliometric analysis relies on the use of the Journal Citation Report (JCR) to construct an adequate list of the core ITS journals. JCR attracts the most important research contributions of the different scientific disciplines because the number publications in indexed JCR journals is considered as a very important criterion in tenure, promotion, and other professional decisions [15], [16]. Indeed, it could be considered as a standard for assessing journal quality across the science disciplines. According to Cobo et al. [3], there are four ITS prominent journals in the latest JCR update (2013): Journal of Intelligent Transportation Systems, ITS Journal, IET Intelligent Transport Systems and IEEE Transactions on Intelligent Transportation Systems.

The documents published in these four journals and their associated citation counts were obtained using the Web of Science (WoS) bibliographic database. WoS provides a complete retrospective quality coverage of ITS and, therefore, it 
is considered appropriate for developing an analysis of highly cited papers.

\section{B. Sample}

The study sample consists of articles indexed in WoS during the time period 1996-2014. This sample is further restricted to full length articles, including literature review articles; items such as book reviews, editorials, corrections, letters, and notes were excluded from the study. Accordingly, the ITS research documents subject to study were retrieved with the following WoS advance search query:

\section{TS=("INTELLIGENT TRANSPORT $*$ ") OR}

$\mathrm{SO}=$ ("Journal of Intelligent Transportation Systems"

OR "ITS Journal" OR "IET Intelligent Transport

Systems" OR "IEEE TRANSACTIONS ON

INTELLIGENT TRANSPORTATION SYSTEMS")

This query produced a total of 2086 documents, and for each document the following information was obtained: authors, affiliations, title, year of publication, citations, sources, abstract and keywords.

\section{Procedure}

Following Garfield's recommendations [10], [17], a common characteristic of studies on highly cited papers is to apply a selection criterion that uses a threshold value to discriminate whether a paper is classed as highly cited or not. This has traditionally been done by using one of the following two approaches: (I) The threshold value is based on the number of citations received; (II) The threshold value is based on the number of highly cited papers to be retrieved. Both approaches share the following drawbacks: neither the scientific evolution of the research areas nor their citation patterns are taken into account. To overcome these issues, the concept of $\mathrm{H}$ Classics, based on the popular H-index [13], was introduced by Martínez et al. [14], which provides an unbiased and fair criterion to construct a systematic search procedure for citation classics in any field of research. Therefore, the H-Classics provides a rigorous and scientific method to discover the most relevant highly cited papers and avoid potential biases of studies of highly cited papers conducted so far.

The H-index was originally introduced by Hirsch [13] to measure the scientific performance of a researcher through his/her publications. Its original definition is:

"A scientist has index $h$ if $h$ of his or her $N_{p}$ papers have at least $h$ citations each, and the other $\left(N_{p}\right.$ -

h) papers have $\leq h$ citations each."

Burrell in [18] pointed out that the H-index identifies the most productive core of an author's output in terms of the most cited papers. For this core, consisting of the first $H$ papers, Rousseau [19] introduced the term Hirsch core (H-core), which can be considered as a group of high-performance publications with respect to the scientist's career [20], which was used by Martínez et al. to introduce the concept of H-Classics in [14]

\footnotetext{
" $H$-Classics of a research area $A$ could be defined as the H-core of A that is composed of the H highly cited papers with more than $H$ citations received."
}

Summarising, the identification process of highly cited papers of a research area via the concept of H-Classics is carried out in the following steps [14]:

1) Bibliographic database selection to retrieve the study sample. There are various bibliographic databases available to perform bibliographic studies, with the three most important ones being: WoS, Scopus, and Google Scholar. On the one hand, Scopus coverage of research literature is broader than WoS. However, journals not covered by WoS but Scopus usually are nationally focused and have a low citation impact. On the other hand, Google Scholar present citation information is not deem accurate and reliable. Thus, for the present study WoS was used based on its indexing of the most reliable research information and its offering of a great number of analysis tools to process it.

2) Setting of the research area study. It is necessary to identify the main research publications related to the area of study, so the set of journals that are traditionally used to disseminate scientific advances in the area needs to be established. In the case of WoS, if the area matches one of the scientific areas within JCR, then it would be straightforward to get the set of journals of interest and therefore the sample of documents to analyse would be easily obtained. Otherwise, an appropriate query would be required to be run to retrieve the sample of relevant documents. In the present study, the query indicated above was run to retrieve the ITS relevant documents. In order to focus on papers published in journals, only article and review type outputs were selected.

3) Computation of the $\mathbf{H}$-index of the research area. To compute the $\mathrm{H}$-index of a research field, it is necessary to establish a ranking of papers according to their citations, that is, the set of documents must be ordered by citations in a decreasing way. The interest here is to locate the first document whose ranking position is below its citation count because the $\mathrm{H}$-index will be the ranking position of the paper immediately above. Although the H-index can be computed manually, as mentioned above there are different tools available in WoS that facilitates its computation for a given set of research documents. In the present study the H-index of ITS research field was found to be 53 .

4) Retrieving the H-core of the research area. At this step, the first $\mathrm{H}$ highly cited papers in the previous ranking are included in the H-core of the research area. The H-Core of the research area includes its $\mathrm{H}$-Classics, so the $\mathrm{H}$ index of a research area is the cardinality of its H-core of the area. In the present study, the identified 53 ITS $\mathrm{H}$-Classics are listed in table form in the Appendix.

\section{HighLY CITED PAPERS OF ITS}

In the following sections the H-core of ITS research field is analyzed. First, the distribution of H-Classic documents per year of publication is analysed. Then, authors, institutions and countries producing the highest number of $\mathrm{H}$-Classic documents are identified. Finally, a conceptual evolution is provided. 


\section{A. Distribution of ITS H-Classic documents per year of pub- lication}

As mentioned before, the current study considered a collection of 2086 documents, 53 of which were classed as $\mathrm{H}$ Classics. The distribution of the H-Classics documents per year of publication is shown in Fig. 1. It is worth noting that none of the $53 \mathrm{H}$-Classic documents were published before year 2000. No research document published after 2010 has been categorised yet as H-Classic. The year with more H-Classic documents published is 2006. The first two research documents classed as $\mathrm{H}$-Classics were published in 2000 by Zhao et al. (2000) [21] and Broggi et al. (2000) [22], respectively. Furthermore, the time period 2002-2007 concentrates the majority of them. It is remarkable the ranking position of the recently published H-Classic document by Wang (2010) [23]. Moreover, although highly cited papers are usually located in remotest years due to citation window, ITS demonstrates that is currently growing fast, as research papers tend to catch the attention of the research community within years of being published.

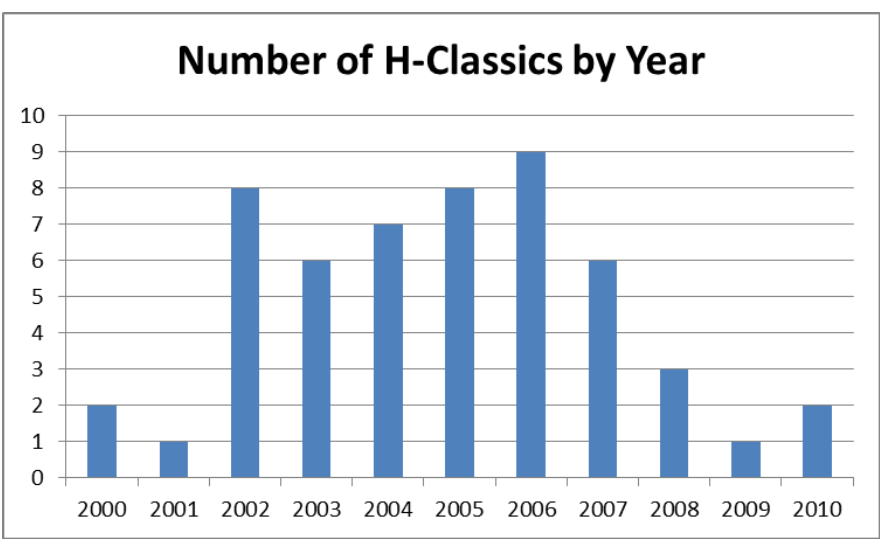

Fig. 1. Distribution of ITS H-Classic documents per year of publication

\section{B. Most productive authors, institutions and countries}

Table I shows the authors with two or more H-Classic documents in the ITS research. Trivedi, affiliated to the Computer Vision \& Robotics research laboratory at University of California San Diego (USA), is the author with the highest number of H-Classic articles. It is worth noting that two other researchers from the same laboratory have published two ITS H-Classic articles: Gandhi and McCall. It should be remarked the presence of six Greek authors: C.N.E. Anagnostopoulos and I.E Anagnostopoulos from University of Aegean; Kayafas and Loumos from National Technical University of Athens; and Kotsialos and Papageorgiou from Technical University of Crete. Moreover, three Spanish researchers from the University of Alcala stand out: L.M. Bergasa, J. Nuevo and M.A. Sotelo.

According to the information on author addresses contained in the research papers, the corresponding institutions and countries can be identified. Table II shows the ranking of institutions with two or more ITS H-Classic papers. The top 3 most productive institutions are the Massachusetts Institute of Technology (USA), the University of Alcala (Spain) and the
TABLE III

Most PRODUCTIVE COUNTRIES OF ITS H-CLASSIC DOCUMENTS

\begin{tabular}{ll}
\hline Country & H-Classics (\%) \\
\hline USA & $34(64.2 \%)$ \\
\hline GREECE & $7(13.2 \%)$ \\
\hline PEOPLES R CHINA & $5(9.43 \%)$ \\
\hline JAPAN & $5(9.43 \%)$ \\
\hline NETHERLANDS & $5(9.43 \%)$ \\
\hline SPAIN & $4(7.55 \%)$ \\
\hline ITALY & $3(5.7 \%)$ \\
\hline AUSTRALIA & $2(3.8 \%)$ \\
\hline GERMANY & $2(3.8 \%)$ \\
\hline SINGAPORE & $2(3.8 \%)$ \\
\hline UK & $2(3.8 \%)$ \\
\hline SWEDEN & $1(1.9 \%)$ \\
\hline
\end{tabular}

University of California San Diego (USA), all of them with three ITS H-Classic papers.

Finally, Table III shows the ranking of countries that originated the ITS H-Classic papers. The leading country is the USA with $34 \mathrm{H}$-Classic documents out of the total 53 , a remarkable figure that nearly quintuplicates the second ranked country, Greece with 7. The predominance of USA in producing ITS H-Classic papers is evident.

\section{Conceptual evolution of ITS H-Classic documents}

In view of the above information, a conceptual evolution of ITS H-Classic documents can be carried out and analyzed.

The first two ITS H-Classic documents [21], [22] date from 2010 and they focused on the research theme pedestrian and vehicle tracking. The first one presents an algorithm to detect pedestrians in a cluttered scene using a pair of moving cameras. The second one uses images taken by vehicles to perceive the environment provides and presents methods for sensing both obstacles and other vehicles.

In 2001 only one document is considered as H-Classic, while in 2002 there are eight papers classed as H-Classics. Tomlin et al. (2001) [24] present an algorithm for generating probably-safe manoeuvres for aircraft in uncertain environments. In 2002 several H-Classic papers are related to traffic management, vehicle tracking and intervehicle communication. It should be noted that $2002 \mathrm{H}$-Classic papers mainly deal with traffic simulation or modeling and resolution of traffic problems [25]-[27].

In 2003 and 2004, there is not a predominant research theme amongst the identified H-Classic papers. In relation to license plate recognition, the paper published by Chang et al. (2004) [28] seems to be relevant in this topic because it presents an experiment to identify license number using a fuzzy algorithm. Moreover, de la Escalera et al. (2004) [29] focused on road sings detection, a subtopic of object recognition. This author developed a system to extract and identify road signs automatically. Finally, there are two remarkable $\mathrm{H}$-Classic papers related to travel time prediction, $\mathrm{Wu}$ et al. and Rice \& Zwet (2004) [30], [31], that contain methods to predict travel-time using different algorithms that control several factors influencing the final travel-time.

The main research themes the H-Classic papers published in 2005 deal with are: traffic management and intervehicle 
TABLE I

MOST PRODUCTIVE AUTHORS OF ITS H-CLASSIC DOCUMENTS

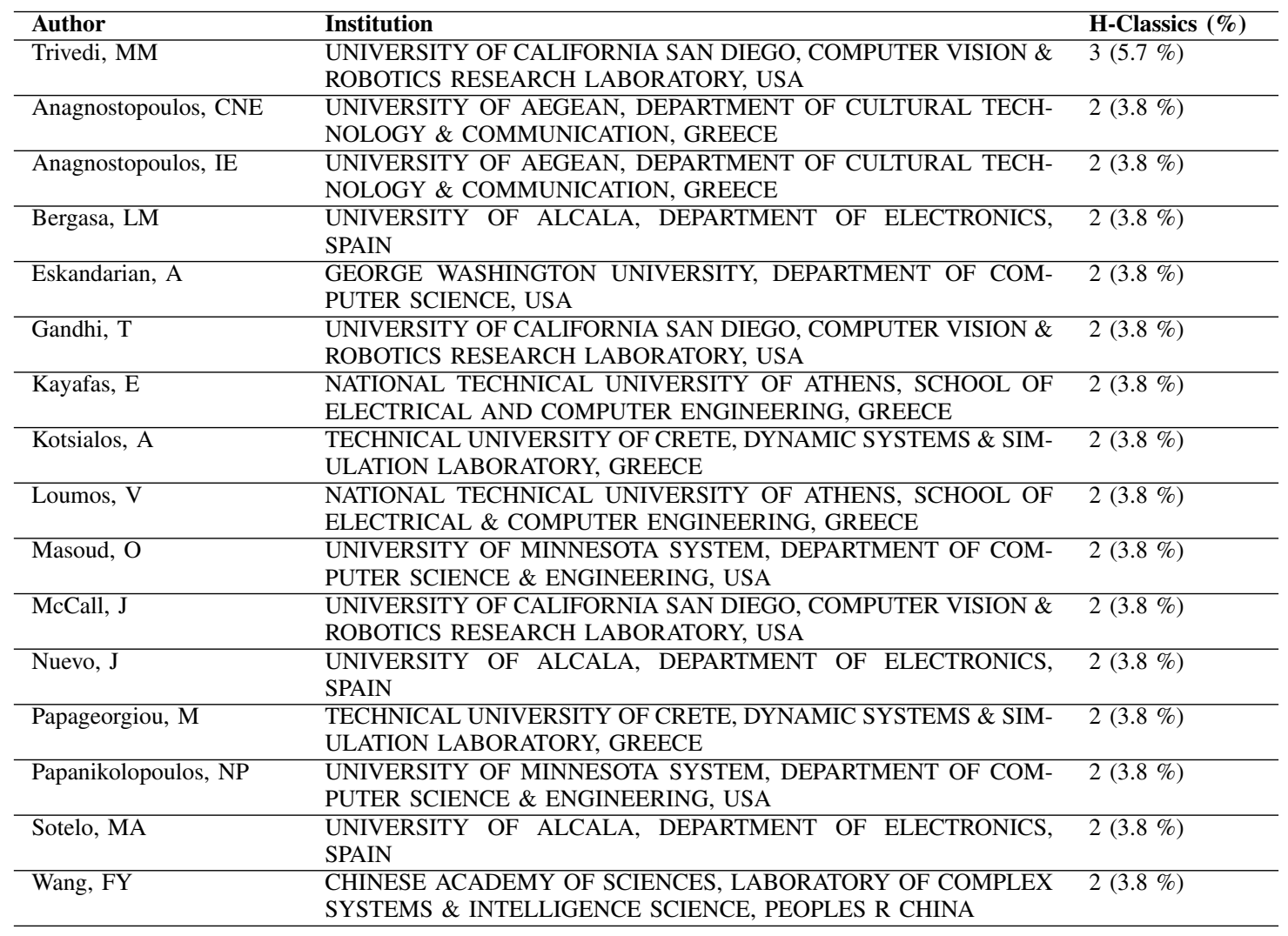

TABLE II

MOST PRODUCTIVE INSTITUTIONS OF ITS H-CLASSIC DOCUMENTS

\begin{tabular}{lll}
\hline Institution & Country & H-Classics $(\boldsymbol{\%})$ \\
\hline MASSACHUSETTS INSTITUTE OF TECHNOLOGY & $3(5.7 \%)$ \\
\hline UNIVERSITY OF ALCALA & USA & $3(5.7 \%)$ \\
\hline UNIVERSITY OF CALIFORNIA SAN DIEGO & SPAIN & $3(5.7 \%)$ \\
\hline CHINESE ACADEMY OF SCIENCES & USA & $2(3.8 \%)$ \\
\hline GEORGE WASHINGTON UNIVERSITY & PEOPLES R CHINA & $2(3.8 \%)$ \\
\hline NATIONAL TECHNICAL UNIVERSITY OF ATHENS & USA & $2(3.8 \%)$ \\
\hline NATIONAL UNIVERSITY OF SINGAPORE & GREECE & $2(3.8 \%)$ \\
\hline TECHNICAL UNIVERSITY OF CRETE & SINGAPORE & $2(3.8 \%)$ \\
\hline TSINGHUA UNIVERSITY & GREECE & $2(3.8 \%)$ \\
\hline UNIVERSITY OF AEGEAN & PEOPLES R CHINA \\
\hline UNIVERSITY OF CALIFORNIA BERKELEY & GREECE & $2(3.8 \%)$ \\
\hline UNIVERSITY OF MINNESOTA & USA & $2(3.8 \%)$ \\
\hline UNIVERSITY OF WASHINGTON & USA \\
\hline
\end{tabular}

communication. This year, the researchers focused on the interpretation of car-following behavior. In particular, the following two H-Classic papers [32], [33] focused on monitoring the behavior of traffic, the former via video analysis and the second using simulation tools.

As mentioned above, the year with more H-Classic papers was 2006, which also counts for the H-Classic paper that has received more citations so far, McCall and Trivedi (2006) [34] with 229 citations. As in previous years, the research topic traffic management has an important research presence this year as well. Other most notable research topics were driver assistance and vechicle tracking. The interest on traffic flow forecasting and traffic control is evident. There are two HClassic documents that focused on those topics, Sun et al.
[35] and Srinivasan et al. [36]. Other research themes HClassic papers dealt with were related to the estimation of lane through video and its tracking to assist the vehicle driver [34], the use of stereo vision to obtain three-dimensional (3D) measurements [37] and tracking and classification of vehicles in real time [38], [39].

From 2007 to 2009, there is a decrease trend on the number of $\mathrm{H}$-Classic papers that cover a wide range of research themes, none of which is predominant. Within this diversity, topics such as map-matching and pedestrian tracking are worth highlight. Quddus et al. (2007) [40] review the literature regarding the available map-matching algorithms; Skog and Handel (2009) [41] provide a survey on positioning and navigation technologies applied to cars; Gandhi and Trivedi 
(2007) [42] present the nature, issues, approaches and challenges surrounding pedestrian safety and collision avoidance, while Parra Alonso et al. (2007) [43] describe a combination of extraction methods of information form video to detect pedestrian.

Regarding the two more recent H-Classic documents published, it is worth remarking that Wang (2010) [23] presents a new mechanism for conducting operations on complex systems with background, concepts, basic methods, major issues, and current applications of Parallel Transportation Management Systems being described; while Chen and Cheng (2010) [44] review the applications of agent-based technology in areas such as modeling and simulation, dynamic routing and congestion management, and intelligent traffic control.

As an overview, it is observed that the four most cited $\mathrm{H}$ Classic papers focus on driver assistance, vehicle tracking, license plate recognition and driver monitoring, respectively. Moreover, the research topics dealt with more frequently within the ITS H-core is related to traffic management, followed by intervehicle communication and vehicle tracking, with almost half of the $\mathrm{H}$-Classic papers dealing with them.

It is remarkable to notice here that the above analysis of the ITS H-core agree with a previous work by Cobo et al. (2014) [3], in which the two research thematic areas in the period 1992-2011 presenting better performance rates based on citation analysis were Vehicle and Road Tracking and Traffic Flow and Traffic Management. Indeed, the analysis presented in this paper means that more than half of the identified H-Classic papers are related to these two thematic areas. Finally, Cobo et al. in [3] found that the most prominent research themes in the period 2002-2006 were Tracking and Behavior, while in the period 2007-2011 these were Tracking, Classification and Recognition, which is corroborated in current study by the presence of a high number of ITS H-Classic papers focused on these research themes.

\section{CONCLUDING REMARKS}

In this paper, ITS highly cited research papers have been analyzed using the concept of H-Classics, which is based on the H-index [13]. The following remarkable findings are highlighted:

- 53 ITS H-Classic papers were identified in the time period 1996-2014, with citation counts ranging from 54 to 229. The H-Classic paper that has received more citations so far is relatively recent and authored by McCall and Trivedi (2006) [34].

- Wang's H-Classic paper (2010) [23], with 102 citations and ranked $14^{t h}$, is also remarkable because articles normally need a long period of time to accumulate citations.

- Almost all H-Classic papers were published in the T-ITS journal (50 out of 53).

- Professor Trivedi, from the University of California San Diego, is the author with more H-Classic papers in the ITS research field. His teaching and research activity is developed in the Computer Vision \& Robotic Research Laboratory.
- The Massachusetts Institute of Technology (USA), the University of Alcala (Spain) and the University of California San Diego (USA) are the main institutional contributors of $\mathrm{H}$-Classic papers.

- The predominance of USA in producing H-Classic papers is evident. However, the presence of European institutions and authors in the top positions is also remarkable. Specifically, it should be pointed out institutions and authors from Greece.

- The four most cited H-Classic papers focus on driver assistance, vehicle tracking, license plate recognition and driver monitoring, respectively.

- The research topics that are addressed more within ITS $\mathrm{H}$-core are traffic management, followed by intervehicle communication and vehicle tracking, with almost half of the H-Classic papers.

Finally, it is worth mentioning the practical application of the present study as it provides a potentially important information to help understand the past, present and future scientific structure of the ITS field that could help its future research development.

\section{ACKNOWLEDGMENT}

J.A. Moral-Muñoz holds a FPU scholarship (AP2012-1789) from the Spanish Ministry of Education.

This work has been supported by the Excellence Andalusian Projects TIC-5299 and TIC-5991, and National Project TIN2010-17876 and TIN2013-40658-P.

\section{REFERENCES}

[1] R. Weiland and L. Purser, "Intelligent transportation systems," Transportation Research Board Business Office, 2000.

[2] L. Figueiredo, I. Jesus, J. Machado, J. Ferreira, and J. de Carvalho, "Towards the development of intelligent transportation systems," Intelligent Transport Systems, 2001. Proceedings. 2001 IEEE, 2001.

[3] M. Cobo, F. Chiclana, A. Collop, J. Oña, and E. Herrera-Viedma, "A bibliometric analysis of the intelligent transportation systems research based on science mapping." IEE Transactions on Intelligent Transportation Systems, vol. 15, no. 2, pp. 901-908, 2014.

[4] F.-Y. Wang, A. Broggi, and C. White, "Road to transactions on intelligent transportation systems: A decade's success," IEEE Transactions on Intelligent Transportation Systems, vol. 10, no. 4, pp. 553-556, 2009.

[5] F.-Y. Wang, "Publication and impact: A bibliographic analysis," IEEE Transactions on Intelligent Transportation Systems, vol. 11, no. 2, p. 250,2010

[6] L. Li, X. Li, C. Cheng, C. Chen, G. Ke, Z. D.D., and W. Scherer, "Research collaboration and iots topic evolution: 10 years at t-its," IEEE Transactions on Intelligent Transportation Systems, vol. 11, no. 3, pp. 517-523, 2010.

[7] M. Cobo, A. López-Herrera, F. Herrera, and E. Herrera-Viedma, "A note on the its topic evolution in the period 2000-2009 at t-its," IEEE Transactions on Intelligent Transportation Systems, vol. 13, no. 1, pp. 413-420, 2012

[8] S. Tang, Z. Li, D. Chen, Z. Chen, W. Liu, X. Liu, L. Li, and X. Shi, "Theme classification and analysis of core articles published in ieee transactions on intelligent transportation systems from 2010 to 2013," IEEE Transactions on Intelligent Transportation Systems, vol. 15, no. 6, pp. 2710-2719, 2014

[9] T. Wang, X. Wang, S. Tang, Y. Lin, W. Liu, Z. Liu, B. Xiu, D. Shen, $\mathrm{X}$. Zhao, and Y. Gao, "Collaborations patterns and productivity analysis for ieee t-its between 2010 and 2013," Intelligent Transportation Systems, IEEE Transactions on, vol. 15, no. 6, pp. 2360-2367, 2014.

[10] E. Garfield, "Introducing citation classics. the human side of scientific reports," Current Comments, vol. 1, pp. 5-7, 1977.

[11] D. Smith, "Ten citation classics from the new zealand medical journal," New Zealand Medical Journal, vol. 120, pp. 2871-2875, 2007. 
[12] S. Stack, "Citation classics in suicide and life treatening behavior: A research note," Suicide nad Life-Threatening Behavior, vol. 42, no. 6 , pp. 628-639, 2012.

[13] J. Hirsch, "An index to quantify an individual's sceitnific research output." Proceedings of hte National Academy of Sciences, vol. 102, pp. 16569-16572, 2005

[14] M. Martínez, M. Herrera, J. López-Gijón, and E. Herrera-Viedma, "Hclassics: Characterizing the concept of citation classics through h-index," Scientometrics, vol. 98, pp. 1971-1983, 2014.

[15] D. R. Hodge and J. R. Lacasse, "Ranking disciplinary journals with the google scholar h-index: A new tool for constructing cases for tenure, promotion, and other professional decisions," Journal of Social Work Education, vol. 47, no. 3, pp. 579-596, 2011.

[16] M. M. Seipel, “Assessing publication for tenure," Journal of Social Work Education, vol. 39, no. 1, pp. 79-88, 2003.

[17] E. Garfield, "100 citation classics from the journal of the american medical association," Journal of the American Medical Association, vol. 257, pp. 52-59, 1987

[18] Q. L. Burrell, "On the h-index, the size of the hirsch core and jin's a-index," Journal of Infometrics, vol. 1, no. 2, pp. 170-177, 2007.

[19] R. Rousseau, "New developments related to the hirsch index." Science Focus, vol. 1, no. 4, pp. 23-25, 2006.

[20] B. Jin, L. Liang, R. Rousseau, and L. Egghe, "The r- and ar-indices: Complementing the h-index," Chinese Science Bulletin, vol. 52, no. 6 , pp. 855-863, 2007.

[21] L. Zhao and C. E. Thorpe, "Stereo- and Neural Network-Based Pedestrian Detection," IEEE Transactions on Intelligent Transportation Systems, vol. 1, no. 3, pp. 148-154, SEP 2000.

[22] A. Broggi, M. Bertozzi, A. Fascioli, C. G. Lo Bianco, and A. Piazzi, "Visual Perception of Obstacles and Vehicles for Platooning," IEEE Transactions on Intelligent Transportation Systems, vol. 1, no. 3, pp. 164-176, SEP 2000.

[23] F.-Y. Wang, "Parallel Control and Management for Intelligent Transportation Systems: Concepts, Architectures, and Applications," IEEE Transactions on Intelligent Transportation Systems, vol. 11, no. 3, pp 630-638, SEP 2010.

[24] C. Tomlin, I. Mitchell, and R. Ghosh, "Safety verification of conflict resolution maneuvers," IEEE Transactions on Intelligent Transportation Systems, vol. 2, no. 2, pp. 110-120, JUN 2001.

[25] P. Hidas, "Modelling lane changing and merging in microscopic traffic simulation," Transportation Research Part C-Emerging Technologies, vol. 10, no. 5-6, pp. 351-371, OCT-DEC 2002.

[26] L. Pallottino, E. Feron, and A. Bicchi, "Conflict resolution problems for air traffic management systems solved with mixed integer programming," IEEE Transactions on Intelligent Transportation Systems, vol. 3 , no. 1, pp. 3-11, MAR 2002, Conference on Intelligent Transportation Systems, DETROIT, MI, OCT 03-05, 2000.

[27] A. Kotsialos, M. Papageorgiou, C. Diakaki, Y. Pavlis, and F. Middelham, "Traffic flow modeling of large-scale motorway networks using the macroscopic modeling tool METANET," IEEE Transactions on Intelligent Transportation Systems, vol. 3, no. 4, pp. 282-292, DEC 2002.

[28] S. Chang, L. Chen, Y. Chung, and S. Chen, "Automatic license plate recognition," IEEE Transactions on Intelligent Transportation Systems, vol. 5, no. 1, pp. 42-53, MAR 2004

[29] A. de la Escalera, J. Armingol, J. Pastor, and F. Rodriguez, "Visua sign information extraction and identification by deformable models for intelligent vehicles," IEEE Transactions on Intelligent Transportation Systems, vol. 5, no. 2, pp. 57-68, JUN 2004.

[30] C. Wu, J. Ho, and D. Lee, "Travel-time prediction with support vector regression," IEEE Transactions on Intelligent Transportation Systems, vol. 5, no. 4, pp. 276-281, DEC 2004, 7th IEEE International Conference on Intelligent Transportation Systems, Washington, DC, 2004.

[31] J. Rice and E. van Zwet, "A simple and effective method for predicting travel times on freeways," IEEE Transactions on Intelligent Transportation Systems, vol. 5, no. 3, pp. 200-207, SEP 2004.

[32] S. Panwai and H. Dia, "Comparative evaluation of microscopic carfollowing behavior," IEEE Transactions on Intelligent Transportation Systems, vol. 6, no. 3, pp. 314-325, SEP 2005.

[33] P. Kumar, S. Ranganath, W. Huang, and K. Sengupta, "Framework for real-time behavior interpretation from traffic video," IEEE Transactions on Intelligent Transportation Systems, vol. 6, no. 1, pp. 43-53, MAR 2005, 6th IEEE International Conference on Intelligent Transportation Systems, SHANGHAI, PEOPLES R CHINA, OCT 12-15, 2003.

[34] J. McCall and M. Trivedi, "Video-based lane estimation and tracking for driver assistance: Survey, system, and evaluation," IEEE Transactions on Intelligent Transportation Systems, vol. 7, no. 1, pp. 20-37, MAR 2006
[35] D. Srinivasan, M. C. Choy, and R. L. Cheu, "Neural networks for realtime traffic signal control," IEEE Transactions on Intelligent Transportation Systems, vol. 7, no. 3, pp. 261-272, SEP 2006.

[36] S. Sun, C. Zhang, and G. Yu, "A Bayesian network approach to traffic flow forecasting," IEEE Transactions on Intelligent Transportation Systems, vol. 7, no. 1, pp. 124-132, MAR 2006.

[37] W. van der Mark and D. Gavrila, "Real-time dense stereo for intelligent vehicles," IEEE Transactions on Intelligent Transportation Systems, vol. 7, no. 1, pp. 38-50, MAR 2006.

[38] J. Hsieh, S. Yu, Y. Chen, and W. Hu, "Automatic traffic surveillance system for vehicle tracking and classification," IEEE Transactions on Intelligent Transportation Systems, vol. 7, no. 2, pp. 175-187, JUN 2006.

[39] L. Li, F. Wang, and Q. Zhou, "Integrated longitudinal and lateral tire/road friction modeling and monitoring for vehicle motion control," IEEE Transactions on Intelligent Transportation Systems, vol. 7, no. 1, pp. 1-19, MAR 2006.

[40] M. A. Quddus, W. Y. Ochieng, and R. B. Noland, "Current mapmatching algorithms for transport applications: State-of-the art and future research directions," Transportation Research Part C-Emerging Technologies, vol. 15, no. 5, pp. 312-328, OCT 2007.

[41] I. Skog and P. Handel, "In-Car Positioning and Navigation TechnologiesA Survey," IEEE Transactions on Intelligent Transportation Systems, vol. 10, no. 1, pp. 4-21, MAR 2009.

[42] T. Gandhi and M. M. Trivedi, "Pedestrian protection systems: Issues, survey, and challenges," IEEE Transactions on Intelligent Transportation Systems, vol. 8, no. 3, pp. 413-430, SEP 2007.

[43] I. Parra Alonso, D. Fernandez Llorca, M. Angel Sotelo, L. M. Bergasa, P. Revenga de Toro, J. Nuevo, M. Ocana, and M. A. Garcia Garrido, "Combination of feature extraction methods for SVM pedestrian detection," IEEE Transactions on Intelligent Transportation Systems, vol. 8 , no. 2, pp. 292-307, JUN 2007.

[44] B. Chen and H. H. Cheng, "A Review of the Applications of Agent Technology in Traffic and Transportation Systems," IEEE Transactions on Intelligent Transportation Systems, vol. 11, no. 2, pp. 485-497, JUN 2010.

José A. Moral-Muñoz was born in 1988. He received the M.Sc. degree in library sciences from the University of Granada, Granada, Spain, in 2012 and currently he is a $\mathrm{PhD}$ student at the same university.

He currently holds a FPU scholarship from the Spanish Ministry of Education with the Department of Library Science, University of Granada, Spain. His research interests include science mapping analysis, bibliometric citation analysis, scientometrics, research evaluation and data visualization.

Manuel J. Cobo was born in 1982. He received the M.Sc. and Ph.D. degrees in computer sciences from the University of Granada, Granada, Spain, in 2008 and 2011, respectively.

He is currently an Associate Professor with the Department of Computer Science and Engineering, University of Cádiz, Spain. His research interests include science mapping analysis, bibliometric, scientometrics, text mining, graph mining, data visualization, quality evaluation, decision making and recommender systems.

Francisco Chiclana received the B.Sc. and Ph.D. degrees in Mathematics, both from the University of Granada (Spain) in 1989 and 2000, respectively.

$\mathrm{He}$ is currently a Professor in Computational Intelligence and Decision Making in the School $\mathrm{f}$ Computer Science and Informatics at De Montfort University (Leicester, UK), and Honorary Professor in the Department of Mathematics at the University of Leicester (2015-2018). Prof. Chiclana is Associate Editor (AE) and Guest Editor for several ISI indexed journals. Additionally, Prof. Chiclana has been Programme Co-chair of IEEE International Conference on System Science and Engineering (ICSSE 2015), Cochair (2007-2014) of the International Conference of Computational Intelligence and Intelligent Systems (London, UK), and he has organised and chaired special sessions/workshops in many major international conferences in research areas relevant to fuzzy preference modelling, decision making problems with heterogeneous fuzzy information, decision support systems, the consensus reaching process, recommender systems, social networks, modelling situations with missing/incomplete information, rationality/consistency, intelligent mobility and aggregation of information. 
Andy Collop was appointed Deputy Vice-Chancellor in February 2015. He joined De Montfort University (DMU) as Pro Vice-Chancellor and Dean of the Faculty of Technology in September 2011 before becoming Pro ViceChancellor for Research and Innovation in 2012.

After completing a BEng in Mechanical Engineering (Council for National Academic Awards) and a PhD in Mechanical/Civil Engineering at the University of Cambridge, Andy was appointed to a lectureship in the Department of Civil Engineering at The University of Nottingham in 1996. He was awarded a Chair in Civil Engineering in 2004, and in 2006 a DSc from The University of Nottingham for his research into pavement and rail track engineering. He has published more than 180 journal and conference papers and is a member of many editorial boards and technical committees.

In 2008, Andy chaired a panel on technology for the built environment for an international research assessment exercise undertaken at The Royal Institute of Technology (KTH) in Sweden. In 2011 he was appointed a member of the Science and Technology Committee of the Shanghai Municipal Commission of Urban and Rural Construction and Transport. With commercial experience principally through links with Scott Wilson, Andy was also director of a joint venture with The University of Nottingham and Scott Wilson Pavement Engineering Ltd.

Enrique Herrera-Viedma was born in 1969. He received the M.Sc. and Ph.D. degrees in computer science from the University of Granada, Granada, Spain, in 1993 and 1996, respectively.

He is currently Vice-Chancellor of Research and Innovation in University of Granada and Professor with the Department of Computer Science and Artificial Intelligence, and member of government of the IEEE System Man and Cybernetic Society. He is Associate Editor of various ISI journals including IEEE Trans. on Syst. Man and Cybernetics: Systems, Knowledge Based Systems, Soft Computing, Journal of Intelligent and Fuzzy Systems, Fuzzy Optimization and Decision Making, Applied Soft Computing, Int. Journal of Fuzzy Systems and Information Sciences; and member of the editorial board of various ISI journals as Fuzzy Sets and Systems, Int. Journal of Information Technology and Decision Making, and Int. J. of Computational Intelligence. His current research interests include group decision making, consensus models, linguistic modeling, aggregation of information, information retrieval, bibliometric, digital libraries, web quality evaluation, and recommender systems.

Prof. Herrera-Viedma's H-index is 46 and presents over 8000 citations according to Web of Science, and he was identified as Highly Cited Researcher by Thomson Reuters in the scientific category Engineering included in the list of Highly Cited Authors published in 2014. 


\section{APPENDIX \\ ITS H-CORE RESEARCH DOCUMENTS LIST}

TABLE IV: H-Classic papers

\begin{tabular}{|c|c|}
\hline Paper & Citations \\
\hline $\begin{array}{l}\text { 1. J. C. McCall, and M. M. Trivedi, "Video-based lane estimation and tracking for driver assistance: Survey, } \\
\text { system, and evaluation," IEEE Transactions on Intelligent Transportation Systems, vol. 7, no. 1, pp. 20-37, Mar, } \\
2006 .\end{array}$ & 229 \\
\hline $\begin{array}{l}\text { 2. S. Gupte, O. Masoud, R. F. K. Martin, and N. P. Papanikolopoulos, "Detection and classification of vehicles," } \\
\text { IEEE Transactions on Intelligent Transportation Systems, vol. 3, no. 1, pp. 37-47, Mar, } 2002 .\end{array}$ & 203 \\
\hline $\begin{array}{l}\text { 3. S. L. Chang, L. S. Chen, Y. C. Chung, and S. W. Chen, "Automatic license plate recognition," IEEE Transactions } \\
\text { on Intelligent Transportation Systems, vol. 5, no. 1, pp. 42-53, Mar, } 2004 .\end{array}$ & 190 \\
\hline $\begin{array}{l}\text { 4. J. A. Healey, and R. W. Picard, "Detecting stress during real-world driving tasks using physiological sensors," } \\
\text { IEEE Transactions on Intelligent Transportation Systems, vol. 6, no. 2, pp. 156-166, Jun, } 2005 .\end{array}$ & 182 \\
\hline $\begin{array}{l}\text { 5. J. J. Blum, A. Eskandarian, and L. J. Hoffman, "Challenges of intervehicle ad hoc networks," IEEE Transactions } \\
\text { on Intelligent Transportation Systems, vol. 5, no. 4, pp. 347-351, Dec, } 2004 .\end{array}$ & 148 \\
\hline $\begin{array}{l}\text { 6. A. Vahidi, and A. Eskandarian, "Research advances in intelligent collision avoidance and adaptive cruise } \\
\text { control," IEEE Transactions on Intelligent Transportation Systems, vol. 4, no. 3, pp. 143-153, Sep, } 2003 .\end{array}$ & 140 \\
\hline $\begin{array}{l}\text { 7. C. H. Wu, J. M. Ho, and D. T. Lee, "Travel-time prediction with support vector regression," IEEE Transactions } \\
\text { on Intelligent Transportation Systems, vol. 5, no. 4, pp. 276-281, Dec, } 2004 .\end{array}$ & 132 \\
\hline $\begin{array}{l}\text { 8. M. Papageorgiou, and A. Kotsialos, "Freeway ramp metering: An overview," IEEE Transactions on Intelligent } \\
\text { Transportation Systems, vol. 3, no. 4, pp. 271-281, Dec, } 2002 \text {. }\end{array}$ & 131 \\
\hline $\begin{array}{l}\text { 9. L. M. Bergasa, J. Nuevo, M. A. Sotelo, R. Barea, and M. E. Lopez, "Real-time system for monitoring driver } \\
\text { vigilance," IEEE Transactions on Intelligent Transportation Systems, vol. 7, no. 1, pp. 63-77, Mar, } 2006 .\end{array}$ & 126 \\
\hline $\begin{array}{l}\text { 10. M. A. Quddus, W. Y. Ochieng, and R. B. Noland, "Current map-matching algorithms for transport applications: } \\
\text { State-of-the art and future research directions," Transportation Research Part C-Emerging Technologies, vol. 15, } \\
\text { no. 5, pp. 312-328, Oct, } 2007 \text {. }\end{array}$ & 119 \\
\hline $\begin{array}{l}\text { 11. L. Zhao, and C. E. Thorpe, "Stereo- and Neural Network-Based Pedestrian Detection," IEEE Transactions on } \\
\text { Intelligent Transportation Systems, vol. 1, no. 3, pp. } 148-154 \text {, Sep, } 2000 .\end{array}$ & 119 \\
\hline $\begin{array}{l}\text { 12. T. Gandhi, and M. M. Trivedi, "Pedestrian protection systems: Issues, survey, and challenges," IEEE } \\
\text { Transactions on Intelligent Transportation Systems, vol. 8, no. 3, pp. 413-430, Sep, } 2007 \text {. }\end{array}$ & 111 \\
\hline $\begin{array}{l}\text { 13. L. Wischhof, A. Ebner, and H. Rohling, "Information dissemination in self-organizing intervehicle networks," } \\
\text { IEEE Transactions on Intelligent Transportation Systems, vol. 6, no. 1, pp. 90-101, Mar, } 2005 .\end{array}$ & 107 \\
\hline $\begin{array}{l}\text { 14. F. Y. Wang, "Parallel Control and Management for Intelligent Transportation Systems: Concepts, Architectures, } \\
\text { and Applications," IEEE Transactions on Intelligent Transportation Systems, vol. 11, no. 3, pp. 630-638, Sep, } \\
2010 .\end{array}$ & 102 \\
\hline $\begin{array}{l}\text { 15. I. Skog, and P. Handel, "In-Car Positioning and Navigation Technologies-A Survey," IEEE Transactions on } \\
\text { Intelligent Transportation Systems, vol. 10, no. 1, pp. 4-21, Mar, } 2009 .\end{array}$ & 99 \\
\hline $\begin{array}{l}\text { 16. F. L. Xu, X. Liu, and K. Fujimura, "Pedestrian detection and tracking with night vision," IEEE Transactions } \\
\text { on Intelligent Transportation Systems, vol. 6, no. 1, pp. 63-71, Mar, } 2005 \text {. }\end{array}$ & 98 \\
\hline $\begin{array}{l}\text { 17. S. Maldonado-Bascon, S. Lafuente-Arroyo, P. Gil-Jimenez, H. Gomez-Moreno, and F. Lopez-Ferreras, "Road- } \\
\text { sign detection and recognition based on support vector machines," IEEE Transactions on Intelligent Transportation } \\
\text { Systems, vol. } 8 \text {, no. 2, pp. 264-278, Jun, } 2007 .\end{array}$ & 96 \\
\hline $\begin{array}{l}\text { 18. S. L. Sun, C. S. Zhang, and G. Q. Yu, "A Bayesian network approach to traffic flow forecasting," IEEE } \\
\text { Transactions on Intelligent Transportation Systems, vol. 7, no. 1, pp. 124-132, Mar, } 2006 .\end{array}$ & 94 \\
\hline $\begin{array}{l}\text { 19. C. N. E. Anagnostopoulos, I. E. Anagnostopoulos, I. D. Psoroulas, V. Loumos, and E. Kayafas, "License plate } \\
\text { recognition from still images and video sequences: A survey," IEEE Transactions on Intelligent Transportation } \\
\text { Systems, vol. } 9 \text {, no. 3, pp. 377-391, Sep, } 2008 \text {. }\end{array}$ & 91 \\
\hline $\begin{array}{l}\text { 20. S. Kato, S. Tsugawa, K. Tokuda, T. Matsui, and H. Fujii, "Vehicle control algorithms for cooperative } \\
\text { driving with automated vehicles and intervehicle communications," IEEE Transactions on Intelligent Transportation } \\
\text { Systems, vol. 3, no. 3, pp. 155-161, Sep, } 2002 \text {. }\end{array}$ & 89 \\
\hline $\begin{array}{l}\text { 21. Z. Kim, "Robust lane detection and tracking in challenging scenarios," IEEE Transactions on Intelligent } \\
\text { Transportation Systems, vol. } 9 \text {, no. } 1 \text {, pp. 16-26, Mar, } 2008 \text {. }\end{array}$ & 88 \\
\hline $\begin{array}{l}\text { 22. Y. H. He, H. Wang, and B. Zhang, "Color-based road detection in urban traffic scenes," IEEE Transactions } \\
\text { on Intelligent Transportation Systems, vol. 5, no. 4, pp. 309-318, Dec, } 2004 .\end{array}$ & 88 \\
\hline $\begin{array}{l}\text { 23. P. Hidas, "Modelling lane changing and merging in microscopic traffic simulation," Transportation Research } \\
\text { Part C-Emerging Technologies, vol. 10, no. 5-6, pp. 351-371, Oct-Dec, } 2002 .\end{array}$ & 87 \\
\hline $\begin{array}{l}\text { 24. P. Smith, M. Shah, and N. D. Lobo, "Determining driver visual attention with one camera," IEEE Transactions } \\
\text { on Intelligent Transportation Systems, vol. 4, no. 4, pp. 205-218, Dec, } 2003 .\end{array}$ & 86 \\
\hline $\begin{array}{l}\text { 25. B. van Arem, C. J. G. van Driel, and R. Visser, "The impact of cooperative adaptive cruise control on traffic- } \\
\text { flow characteristics, "IEEE Transactions on Intelligent Transportation Systems, vol. 7, no. 4, pp. 429-436, Dec, } \\
2006 \text {. }\end{array}$ & 83 \\
\hline $\begin{array}{l}\text { 26. C. N. E. Anagnostopoulos, I. E. Anagnostopoulos, V. Loumos, and E. Kayafas, "A license plate-recognition } \\
\text { algorithm for intelligent transportation system applications," IEEE Transactions on Intelligent Transportation } \\
\text { Systems, vol. 7, no. } 3 \text {, pp. } 377-392 \text {, Sep, } 2006 \text {. }\end{array}$ & 81 \\
\hline $\begin{array}{l}\text { 27. J. Zhu, and S. Roy, "MAC for dedicated short range communications in intelligent transport system," IEEE } \\
\text { Communications Magazine, vol. } 41 \text {, no. } 12 \text {, pp. } 60-67, \text { Dec, } 2003 \text {. }\end{array}$ & 81 \\
\hline $\begin{array}{l}\text { 28. I. Sen, and D. W. Matolak, "Vehicle-vehicle channel models for the 5-GHz band," IEEE Transactions on } \\
\text { Intelligent Transportation Systems, vol. } 9 \text {, no. } 2 \text {, pp. } 235-245 \text {, Jun, } 2008 .\end{array}$ & 80 \\
\hline $\begin{array}{l}\text { 29. C. S. Patel, G. L. Stuber, and T. G. Pratt, "Simulation of Rayleigh-faded mobile-to-mobile communication } \\
\text { channels," IEEE Transactions on Communications, vol. 53, no. 11, pp. 1876-1884, Nov, } 2005 \text {. }\end{array}$ & 78 \\
\hline
\end{tabular}


TABLE IV - Continue from previous page

Paper

30. L. Pallottino, E. M. Feron, and A. Bicchi, "Conflict resolution problems for air traffic management systems solved with mixed integer programming," IEEE Transactions on Intelligent Transportation Systems, vol. 3, no. 1, pp. 3-11, Mar, 2002.

31. J. W. Hsieh, S. H. Yu, Y. S. Chen, and W. F. Hu, "Automatic traffic surveillance system for vehicle tracking and classification," IEEE Transactions on Intelligent Transportation Systems, vol. 7, no. 2, pp. 175-187, Jun, 2006.

32. A. Hegyi, B. De Schutter, and J. Hellendoorn, "Optimal coordination of variable speed limits to suppress shock waves," IEEE Transactions on Intelligent Transportation Systems, vol. 6, no. 1, pp. 102-112, Mar, 2005.

33. A. de la Escalera, J. M. Armingol, J. M. Pastor, and F. J. Rodriguez, "Visual sign information extraction and identification by deformable models for intelligent vehicles," IEEE Transactions on Intelligent Transportation Systems, vol. 5, no. 2, pp. 57-68, Jun, 2004.

34. M. M. Trivedi, T. Gandhi, and J. McCall, "Looking-in and looking-out of a vehicle: Computer-vision-based 68 enhanced vehicle safety," IEEE Transactions on Intelligent Transportation Systems, vol. 8, no. 1, pp. 108-120, Mar, 2007.

35. S. Panwai, and H. Dia, "Comparative evaluation of microscopic car-following behavior," IEEE Transactions 66 on Intelligent Transportation Systems, vol. 6, no. 3, pp. 314-325, Sep, 2005.

36. H. Veeraraghavan, O. Masoud, and N. P. Papanikolopoulos, "Computer vision algorithms for intersection 66 monitoring," IEEE Transactions on Intelligent Transportation Systems, vol. 4, no. 2, pp. 78-89, Jun, 2003.

37. C. Hatipoglu, U. Ozguner, and K. A. Redmill, "Automated lane change controller design,” IEEE Transactions 65 on Intelligent Transportation Systems, vol. 4, no. 1, pp. 13-22, Mar, 2003.

38. J. Rice, and E. van Zwet, "A simple and effective method for predicting travel times on freeways," IEEE 64 Transactions on Intelligent Transportation Systems, vol. 5, no. 3, pp. 200-207, Sep, 2004.

39. L. Li, F. Y. Wang, and Q. Z. Zhou, "Integrated longitudinal and lateral tire/road friction modeling and 63 monitoring for vehicle motion control," IEEE Transactions on Intelligent Transportation Systems, vol. 7, no. 1, pp. 1-19, Mar, 2006.

40. A. Kotsialos, M. Papageorgiou, C. Diakaki, Y. Pavlis, and F. Middelham, "Traffic flow modeling of largescale motorway networks using the macroscopic modeling tool METANET," IEEE Transactions on Intelligent Transportation Systems, vol. 3, no. 4, pp. 282-292, Dec, 2002.

41. B. Chen, and H. H. Cheng," A Review of the Applications of Agent Technology in Traffic and Transportation 61 Systems," IEEE Transactions on Intelligent Transportation Systems, vol. 11, no. 2, pp. 485-497, Jun, 2010.

42. A. Broggi, M. Bertozzi, A. Fascioli, C. G. Lo Bianco, and A. Piazzi, "Visual Perception of Obstacles and 61 Vehicles for Platooning," IEEE Transactions on Intelligent Transportation Systems, vol. 1, no. 3, pp. 164-176, Sep, 2000.

43. P. Kumar, S. Ranganath, W. M. Huang, and K. Sengupta, "Framework for real-time behavior interpretation from traffic video," IEEE Transactions on Intelligent Transportation Systems, vol. 6, no. 1, pp. 43-53, Mar, 2005.

44. T. N. Schoepflin, and D. J. Dailey, "Dynamic camera calibration of roadside traffic management cameras for vehicle speed estimation," IEEE Transactions on Intelligent Transportation Systems, vol. 4, no. 2, pp. 90-98, Jun, 2003.

45. W. van der Mark, and D. M. Gavrila, "Real-time dense stereo for intelligent vehicles," IEEE Transactions on 59 Intelligent Transportation Systems, vol. 7, no. 1, pp. 38-50, Mar, 2006.

46. I. Chabini, and S. Lan, "Adaptations of the $\mathrm{A}^{*}$ algorithm for the computation of fastest paths in deterministic 59 discrete-time dynamic networks," IEEE Transactions on Intelligent Transportation Systems, vol. 3, no. 1, pp. 60-74, Mar, 2002.

47. C. Tomlin, I. Mitchell, and R. Ghosh, "Safety verification of conflict resolution manoeuvers," IEEE Transactions 58 on Intelligent Transportation Systems, vol. 2, no. 2, pp. 110-120, Jun, 2001.

48. D. Srinivasan, M. C. Choy, and R. L. Cheu, "Neural networks for real-time traffic signal control," IEEE 56 Transactions on Intelligent Transportation Systems, vol. 7, no. 3, pp. 261-272, Sep, 2006.

49. Z. H. Sun, G. Bebis, and R. Miller, "On-road vehicle detection using evolutionary Gabor filter optimization," 56 IEEE Transactions on Intelligent Transportation Systems, vol. 6, no. 2, pp. 125-137, Jun, 2005.

50. G. A. Giannopoulos, T"he application of information and communication technologies in transport," European 56 Journal of Operational Research, vol. 152, no. 2, pp. 302-320, Jan, 2004.

51. C. I. Liu, H. Jula, and P. A. Ioannou, "Design, simulation, and evaluation of automated container terminals," 56 IEEE Transactions on Intelligent Transportation Systems, vol. 3, no. 1, pp. 12-26, Mar, 2002.

52. I. P. Alonso, D. F. Llorca, M. A. Sotelo, L. M. Bergasa, P. R. de Toro, J. Nuevo, M. Ocana, and M. A. 55 G. Garrido, "Combination of feature extraction methods for SVM pedestrian detection," IEEE Transactions on Intelligent Transportation Systems, vol. 8, no. 2, pp. 292-307, Jun, 2007.

53. Y. L. Liang, M. L. Reyes, and J. D. Lee, "Real-time detection of driver cognitive distraction using support 54 vector machines," IEEE Transactions on Intelligent Transportation Systems, vol. 8, no. 2, pp. 340-350, Jun, 2007. 